\title{
Effect of Selected Fabric Construction Elements on Wicking Rates of PET Fabrics
}

Nassar $K^{*}$ and Abou-Taleb E M

Department of Spinning, Weaving and Knitting, Faculty of Applied Arts, Helwan University, Egypt

\begin{abstract}
Apparel has an important role in keeping the body comfortable by maintaining the needed equilibrium state between the human body and the environment by getting rid of sweat which is exerted due to the physical activity. This happens through a multitude of mechanisms, one being the capillary action which is also known as wicking. Wicking is defined as "A spontaneous transport of liquid driven into a porous system by capillary forces". This paper is concerned by studying effect of basic fabric weaves and weft densities of synthetic fabrics (PET) on vertical and horizontal wicking rates and their relation to fabric packing factor. For this aim, 9 samples $100 \%$ PET woven samples varying in weave type (plain 1/1-basket 2/2-twill 1/3) and three pick densities were produced, taking into account that the other production parameters were constant.
\end{abstract}

The experiment showed that wicking rate was influenced by fabric porosity. Vertical wicking rate increases with the increase of the porosity, while horizontal wicking rate decreases with the increase of porosity.

Keywords: Comfort; Wicking rate; Packing factor; Porosity; Weave; Density; PET

\section{Introduction}

Comfort can be defined as a pleasant physical, physiological and psychological equilibrium state between the human being and the environment, and apparel plays an important role in achieving this equilibrium. This is due to that any effort exerted by humans will be translated into metabolic heat which is then dissipated through the clothing as sweat. A human body will produce about $60 \mathrm{ml}$ to $840 \mathrm{ml}$ of water vapour per hour depending on the level of effort exerted by the person $[1,2]$. As a consequence, any clothing should be able to evaporate the perspiration from the skin surface and to transfer the moisture from the layer adjacent to the skin to the outer surface of the fabric and eventually allowing the moisture to evaporate in the atmosphere, this is known as moisture management, where the fabric will eventually dry and wearer will feel more comfortable [2,3]. Drawing the moisture to the outer surface of the fabric is mainly achieved through capillary action which is also known as wicking [2]. Wicking can be defined as "the ability to sustain capillary flow" [4] or as "A spontaneous transport of liquid driven into a porous system by capillary forces" [5]. The phenomenon of capillarity in porous media, as in textiles, results from two opposing forces, liquid adhesion to solid surfaces that tends to spread the liquid, and the cohesive surface tension force of liquids and thus this phenomenon are dependent on solid and liquid interfacial properties such as surface tension, contact angle, and solid surface roughness and geometry [6]. As a result the finer the fibres, the smaller the gaps are, and the better the humidity transport [2].

Water vapour and the liquid water are transmitted through textiles by the following mechanisms:

- Simple diffusion through inter thread spaces: Diffusion is the main mechanism for transferring moisture that is controlled by the water vapour pressure gradient across the inner and outer faces of the fabric.

- Capillary transfer through fibre bundles: the liquid water is "Wicked" through the threads and desorbed or evaporated at the outer surface. That determined by the choice of thread and fabric construction which is the main interest of this study.
- Diffusion through individual fibres: This mechanism involves absorption of water vapour into the fibres at the inner surface of the fabric, diffusion through the fibre structure, and desorption at the outer surface. The ability of fibres to undergo water vapour diffusion depends on the hydrophilic or hydrophobic nature of the fibre [2,7].

The dimensions and structure of inter and intra thread pores is greatly caused by the density and structure of threads in woven fabrics. Inter-fibre pores can be either inter or intra-thread structures. Interthread pores can be similar in size to fibres and in some cases larger than threads. The overall complexity of fabric pore structures must therefore include the complex structural variables, pore size distribution, pore connectivity and total pore volume [8].

Some studies combined several fabric properties to describe the relationship between the fabric packing factor and porosity of a fabric as the following equations.

Packing factor=fabric density

$$
\text { Packing factor }=\frac{\text { fabric density }}{\text { fiber density }}
$$

The packing factor indicates the degree of porosity of the fabric where porosity is defined as the amount of open spaces in the unit volume of fabric [9] which depends generally on the fabric and threads construction. Therefore the packing factor is regarded as an opposite to the porosity. This relation is guarded by the following equations: $[8,10]$.

Porosity=1-Parking factor

*Corresponding author: Nassar K, Department of Spinning, Weaving and Knitting, Faculty of Applied Arts, Helwan University, Egypt, Tel. 202-25565820; E-mail: khaled.mansour@gmail.com

Received February 13, 2014; Accepted March 11, 2014; Published March 15 2014

Citation: Nassar K, Abou-Taleb EM (2014) Effect of Selected Fabric Construction Elements on Wicking Rates of PET Fabrics. J Textile Sci Eng 4: 158 doi:10.4172/2165-8064.1000158

Copyright: @ 2014 Nassar K, et al. This is an open-access article distributed under the terms of the Creative Commons Attribution License, which permits unrestricted use, distribution, and reproduction in any medium, provided the original author and source are credited. 
Citation: Nassar K, Abou-Taleb EM (2014) Effect of Selected Fabric Construction Elements on Wicking Rates of PET Fabrics. J Textile Sci Eng 4: 158. doi:10.4172/2165-8064.1000158

Page 2 of 5

$\because$ Porosity $=1-\frac{\text { medium vol. }}{\text { Bulk vol. }}$

$\therefore$ Porosity $=1-\frac{p b}{p s}$

And for fabrics:

$p b=$ fabric density $\left(\mathrm{g} / \mathrm{cm}^{3}\right)$

$P s=$ fiber density

$$
\therefore P b=\frac{\text { fabric weight }\left(\mathrm{g} / \mathrm{cm}^{3}\right)}{\text { Thickness }(\mathrm{cm})}
$$

This study is concerned with studying the effect of selected weaves and densities on the horizontal and vertical wicking rate of fabrics.

\section{Materials and Methods}

To investigate the effect of the selected weaves and densities on the horizontal and vertical wicking properties, 9 samples were produced as listed in Table 1. For all samples the warp densities were 72 warps $/ \mathrm{cm}$ and the fibre material was PET for both warp and picks to minimize the effect of absorption. In addition, three main weave categories (plain 1/1 -basket 2/2-twill 1/3), and three pick densities for each selected weave. The pick density was chosen according to the maximum pick density that could be woven on the loom without causing any mechanical problems. Therefore the pick densities were set at 40,36 , and 32 picks $/ \mathrm{cm}$. All samples were tested for vertical and horizontal wicking according to AATCC test method 197-2011 for vertical wicking of textiles [11], and AATCC test method 198-2011 for horizontal wicking of textiles [12]. For the vertical wicking test the standard specifies either a $20 \mathrm{~mm}$ or $150 \mathrm{~mm}$ as a measuring distance and for this study the 150 mm method was adopted.

\section{Results and Discussions}

Results of the vertical wicking tests are listed in Tables 2 and 3 respectively. Whereas results of the horizontal wicking tests are listed in Tables 4 and 5 respectively.

Moreover, results for vertical and horizontal wicking rates were grouped according to weaves and densities as shown in Tables 3 and 4 respectively for vertical wicking results, and Tables 5 and 6 for horizontal wicking results. For each group one way ANOVA test was conducted to measure the significance of the results within the tested groups, see Annexure A1 for vertical wicking results and A2 for horizontal wicking results.

\begin{tabular}{|c|c|c|c|c|}
\hline \multicolumn{5}{|c|}{ Specifications of fabrics } \\
\hline Sample no. & Fibre type & Weave type & $\begin{array}{c}\text { Warp density/ } \\
\text { cm }\end{array}$ & $\begin{array}{c}\text { Pick density/ } \\
\text { cm }\end{array}$ \\
\hline-1 & PET & plain1/1 & 72 & 40 \\
\hline-2 & PET & basket 2/2 & 72 & 40 \\
\hline-3 & PET & twill 1/3 & 72 & 40 \\
\hline-4 & PET & plain1/1 & 72 & 36 \\
\hline-5 & PET & basket 2/2 & 72 & 36 \\
\hline-6 & PET & twill 1/3 & 72 & 36 \\
\hline-7 & PET & plain1/1 & 72 & 32 \\
\hline-8 & PET & basket 2/2 & 72 & 32 \\
\hline-9 & PET & twill 1/3 & 72 & 32 \\
\hline
\end{tabular}

Table 1: Specifications of produced test samples.

\begin{tabular}{|c|c|c|c|c|}
\hline Group & Sample no & $\begin{array}{l}\text { Pick density } / \\
\text { cm }\end{array}$ & Weave type & $\begin{array}{l}\text { Vertical wicking } \\
\text { rate }(\mathrm{mm} / \mathrm{sec})\end{array}$ \\
\hline \multirow{3}{*}{1} & -1 & \multirow{3}{*}{40} & plain1/1 & 0.2 \\
\hline & -2 & & basket $2 / 2$ & 0.4 \\
\hline & -3 & & twill $1 / 3$ & 0.3 \\
\hline \multirow{3}{*}{2} & -4 & \multirow{3}{*}{36} & plain1/1 & 0.2 \\
\hline & -5 & & basket 2/2 & 0.4 \\
\hline & -6 & & twill $1 / 3$ & 0.4 \\
\hline \multirow{3}{*}{3} & -7 & \multirow{3}{*}{32} & plain1/1 & 0.2 \\
\hline & -8 & & basket $2 / 2$ & 0.5 \\
\hline & -9 & & twill $1 / 3$ & 0.5 \\
\hline
\end{tabular}

Table 2: Results of vertical wicking test grouped by densities.

\begin{tabular}{|c|c|c|c|c|}
\hline Group & Sample no & Weave type & $\begin{array}{l}\text { Pick density } / \\
\text { cm }\end{array}$ & $\begin{array}{l}\text { Vertical wicking } \\
\text { rate }(\mathrm{mm} / \mathrm{sec})\end{array}$ \\
\hline \multirow{3}{*}{4} & -1 & \multirow{3}{*}{ Plain 1/1 } & 40 & 0.2 \\
\hline & -4 & & 36 & 0.2 \\
\hline & -7 & & 32 & 0.2 \\
\hline \multirow{3}{*}{5} & -2 & \multirow{3}{*}{ Basket 2/2 } & 40 & 0.4 \\
\hline & -5 & & 36 & 0.4 \\
\hline & -8 & & 32 & 0.5 \\
\hline \multirow{3}{*}{6} & -3 & \multirow{3}{*}{ Twill 1/3 } & 40 & 0.3 \\
\hline & -6 & & 36 & 0.4 \\
\hline & -9 & & 32 & 0.5 \\
\hline
\end{tabular}

Table 3: Results of vertical wicking test grouped by weaves.

\begin{tabular}{|c|c|c|c|c|}
\hline Group & Sample no & $\begin{array}{c}\text { Pick density/ } \\
\text { cm }\end{array}$ & Weave type & $\begin{array}{l}\text { Horizontal wicking } \\
\text { rate }(\mathrm{mm} / \mathrm{sec})\end{array}$ \\
\hline \multirow{3}{*}{1} & -1 & \multirow{3}{*}{40} & plain1/1 & 13.5 \\
\hline & -2 & & basket $2 / 2$ & 13.2 \\
\hline & -3 & & twill 1/3 & 9.3 \\
\hline \multirow{3}{*}{2} & -4 & \multirow{3}{*}{36} & plain1/1 & 12.9 \\
\hline & -5 & & basket $2 / 2$ & 9.8 \\
\hline & -6 & & twill 1/3 & 8.7 \\
\hline \multirow{3}{*}{3} & -7 & \multirow{3}{*}{32} & plain1/1 & 9.8 \\
\hline & -8 & & basket $2 / 2$ & 10.9 \\
\hline & -9 & & twill $1 / 3$ & 9.1 \\
\hline
\end{tabular}

Table 4: Results of horizontal wicking test grouped by densities.

\begin{tabular}{|c|c|c|c|c|}
\hline Group & Sample no & Weave type & $\begin{array}{l}\text { Pick density } / \\
\text { cm }\end{array}$ & $\begin{array}{l}\text { Horizontal wicking } \\
\text { rate }(\mathrm{mm} / \mathrm{sec})\end{array}$ \\
\hline \multirow{3}{*}{4} & -1 & \multirow{3}{*}{ Plain 1/1 } & 40 & 13.5 \\
\hline & -4 & & 36 & 12.9 \\
\hline & -7 & & 32 & 9.8 \\
\hline \multirow{3}{*}{5} & -2 & \multirow{3}{*}{ Basket 2/2 } & 40 & 13.2 \\
\hline & -5 & & 36 & 9.8 \\
\hline & -8 & & 32 & 10.9 \\
\hline \multirow{3}{*}{6} & -3 & \multirow{3}{*}{ Twill 1/3 } & 40 & 9.3 \\
\hline & -6 & & 36 & 8.7 \\
\hline & -9 & & 32 & 9.1 \\
\hline
\end{tabular}

Table 5: Results of horizontal wicking test grouped by weaves.

\section{Effect of weave on vertical wicking rate}

After analyzing the ANOVA results for vertical wicking, as listed in Annexure A1, only the 32 picks/cm group was found to be significant $(\mathrm{F}=28.5 \geq \mathrm{Fcrit}=5.143)$. As illustrated in Figure 1, the vertical wicking rates of basket $2 / 2$ and twill $1 / 3$ are higher than that of the plain $1 / 1$ weave fabrics for the given density. This can be explained by the higher porosity of both basket and twill weave fabrics when compared to that of the plain one as observed in Table 6. The higher porosity leads to the 
Citation: Nassar K, Abou-Taleb EM (2014) Effect of Selected Fabric Construction Elements on Wicking Rates of PET Fabrics. J Textile Sci Eng 4: 158. doi: $10.4172 / 2165-8064.1000158$

Page 3 of 5

\begin{tabular}{|c|c|c|}
\hline Weave type & Pick density (picks/cm) & Porosity \\
\hline plain 1/1 & \multirow{2}{*}{32} & 0.34 \\
\hline basket 2/2 & & 0.45 \\
\hline twill 1/3 & & 0.43 \\
\hline
\end{tabular}

Table 6: Porosity of different weaves at 32/picks/cm

\begin{tabular}{|c|c|c|}
\hline Weave type & Pick density (picks/cm) & Porosity \\
\hline twill 1/3 & 40 & 0.37 \\
\hline twill1/3 & 36 & 0.45 \\
\hline twill 1/3 & 32 & 0.43 \\
\hline
\end{tabular}

Table 7: Porosity of different densities for twill weaves samples.

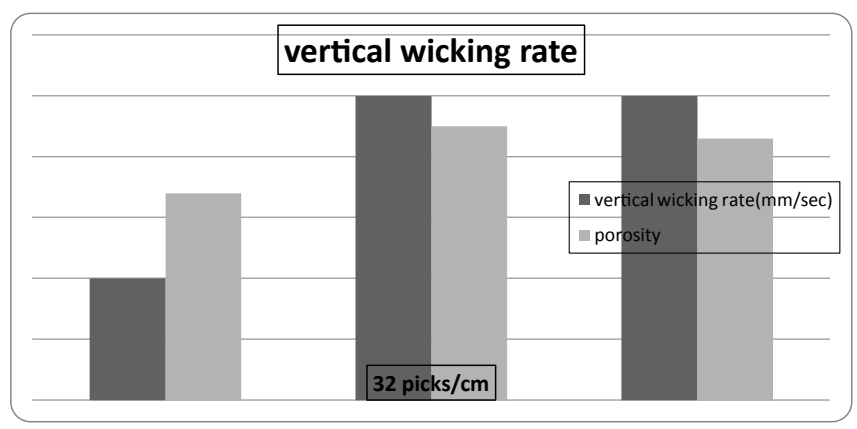

Figure 1: Vertical wicking rate and fabric porosity at density of 32 picks $/ \mathrm{cm}$.

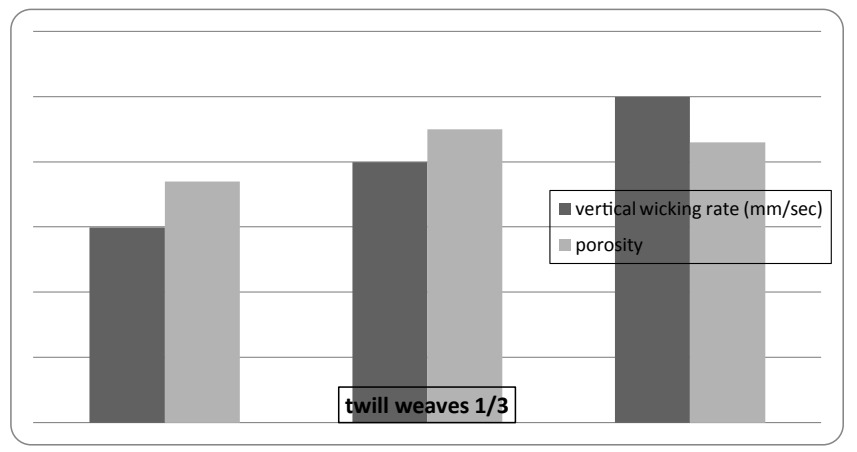

Figure 2: Vertical wicking rate and fabric porosity of twill weaves.

formation of more passages (inter fiber, intra fiber, inter threads, intra threads). And as the vertical wicking depends primarily on the capillary phenomenon, the increase in pores assumes the probability of more capillary passages formation and thus higher wicking rates.

\section{Effect of density on vertical wicking rate}

When results were grouped according to weave type, as shown in Table 4 and ANOVA was conducted it was found out that only the vertical wicking results for the twill weave in group three proved to be significant $(\mathrm{F}=19 \geq \mathrm{Fcrit}=5.143)$ as listed in Annexure A1. As shown in Figure 2, it is observed that the vertical wicking rate of twill weave fabric at density 32 and 36 picks/cm are higher than that of the same weave at 40 picks/ $\mathrm{cm}$. This can be attributed to the fact that the porosity at 32 and 36 picks/ $\mathrm{cm}$ is higher than that of the 40 picks/cm sample as listed in Table 7 . Consequently, this leads to the formation of more capillary passages as aforementioned and thus higher wicking rates are achieved.

\section{Effect of weave on horizontal wicking rate}

After analyzing the ANOVA results for horizontal wicking, as listed in Annexure A2, only the 36 picks/cm group was found to be significant $(\mathrm{F}=6.6 \geq \mathrm{Fcrit}=5.143)$. Accordingly, the rate of wicking of plain $1 / 1$ weave fabrics is higher than that of the basket $2 / 2$ weave and twill $1 / 3$ fabrics as seen in Table 5 .

This can be attributed to the fact that although along each warp and pick thread one intersection occurs per repeat for all weaves, in twill and basket weaves the intersection repeats every 4 threads. In comparison, in plain weave it takes only 2 threads for the intersection to repeat again as shown in Figure 3.

Consequently, this is translated in double the intersections for the plain weave when compared to that of twill and basket weaves. As a result the higher horizontal wicking rate can be attributed to the fact that every intersection point acts as a routing point to the flow of the water which in turn is translated in higher wicking rates.

By examining the relation between packing factor and horizontal wicking rate, it was found that when the packing factor increases the horizontal wicking rate increases and vice versa as listed in Table 8. In addition, by examining the results of the porosity of the given samples as shown in Table 9 it was found that with the increase of the porosity the horizontal wicking rate decreases. And as the packing factor is inversely proportional with the porosity (porosity=1-packing factor) it is believed that with the increase of the porosity and decrease of the packing factor the liquid travels through plane instead in the horizontal direction which is the direction of the horizontal wicking test.

Moreover, the higher horizontal wicking rate of the basket $2 / 2$ weave when compared to the twill $1 / 3$ despite the same pick cover factor $(\mathrm{K} 2=17.86)$ can be attributed to the shorter float length of the twill weave when compared to that of the basket weave. In addition, the float for the basket $2 / 2$ weave is compromised of 2 threads in both directions. In comparison to that of the basket, the float for the twill $1 / 3$ weave is accomplished by only one thread, which in turn results in slower wicking, rates when compared to that of the basket weave.

Which reveal that with the increase of the porosity the horizontal wicking rate decreases. And as the packing factor is inversely proportional with the porosity (porosity $=1$-packing factor) it is believed that with the increase of the porosity and decrease of the backing factor the liquid travels through plane instead in the horizontal direction which is the direction of the horizontal wicking test.

\begin{tabular}{|c|c|c|}
\hline Weave type & Pick density (picks/cm) & packing factor \\
\hline plain1/1 & \multirow{2}{*}{36} & 0.4 \\
\hline basket 2/2 & & 0.3 \\
\hline twill 1/3 & & 0.27 \\
\hline
\end{tabular}

Table 8: Packing factor of different weaves at 36 (picks $/ \mathrm{cm})$.

\begin{tabular}{|c|c|c|}
\hline Weave type & pick density & \multirow{2}{*}{ packing factor } \\
\cline { 1 - 1 } & (picks/cm) & \\
\hline plain1/1 & \multirow{3}{*}{36} & 0.33 \\
\hline basket 2/2 & & 0.42 \\
\hline twill 1/3 & & 0.45 \\
\hline
\end{tabular}

Table 9: Porosity of different weaves at 36 (picks/cm).

\begin{tabular}{|c|c|c|}
\hline Weave type & pick density (picks/cm) & Packing factor \\
\hline plain1/1 & 40 & 0.4 \\
\hline plain1/1 & 36 & 0.4 \\
\hline plain1/1 & 32 & 0.39 \\
\hline
\end{tabular}

Table 10: Packing factor of different densities for plain 1/1 weave samples. 


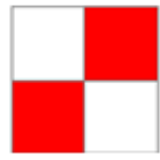

Plain 1/1

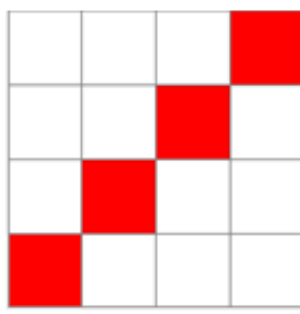

Twill 1/3

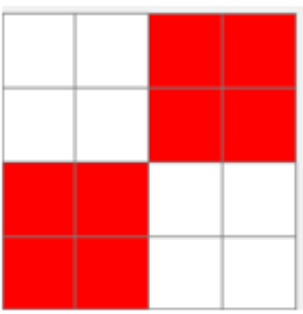

Basket 2/2

1 repeat

1 repeat

1 repeat

1 intersection every 2 threads

1 intersection every 4 threads

1 intersection every 4 threads
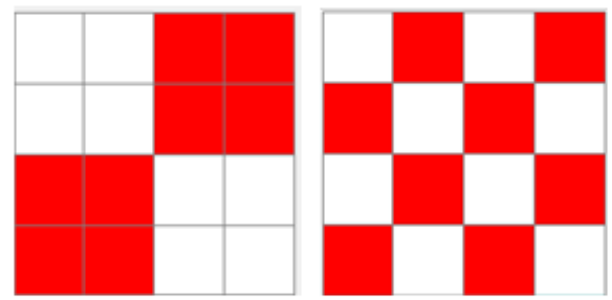

Basket 2/2 (1 repeat) and Plain 1/1

( 2 repeats)
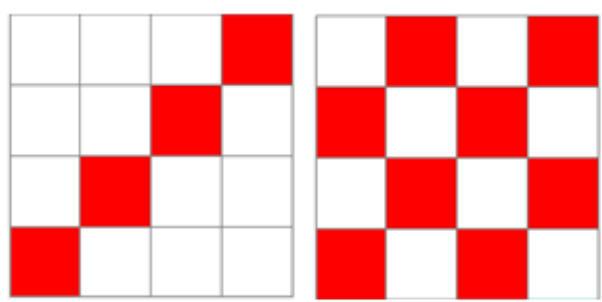

Twill 2/2 (1 repeat) and Plain 1/1

\section{[1 intersection twill 1/3 - 2 intersections plain 1/1 [1 intersection twill 1/3 - 2 intersections every 4 threads] plain $1 / 1$ every 4 threads]}

Figure 3: Number of intersection points of different weaves per 4 threads.

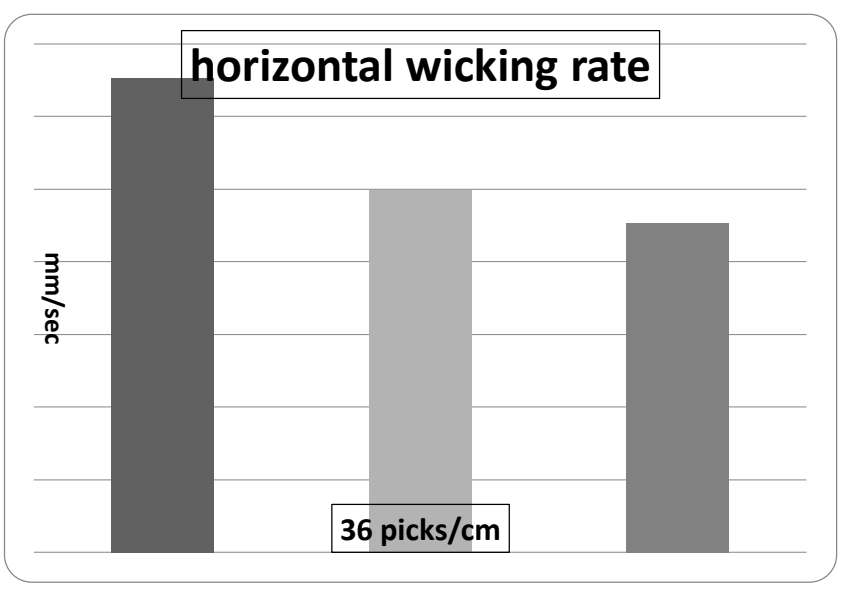

Figure 4: Horizontal wicking rate at density 36 picks $/ \mathrm{cm}$.

Moreover, the higher horizontal wicking rate of the basket $2 / 2$ weave when compared to the twill $1 / 3$ despite the same pick cover factor $(K 2=17.86)$ can be attributed to the longer float length of the twill weave when compared to that of the basket weave. This in turn leads to decreased routing points in the twill sample as the liquid is intercepted every three threads instead of two threads when compared to that of the basket sample. Consequently, this results in slower wicking rates when compared to that of the basket weave (Figure 4).

\section{Effect of density on horizontal wicking rate}

After analyzing the ANOVA results for horizontal wicking, as listed in Annexure A2, results for the plain 1/1 weave in group one as listed in Table 5 proved to be significant $(\mathrm{F}=6.86 \geq \mathrm{Fcrit}=5.143)$.

By reviewing results of packing factor for each density for the aforementioned weave, as tabulated in Table 10 it can be observed that when density increases, the packing factor increases. Consequently, the number of intersections/cm increases. Accordingly, the higher horizontal wicking rate, as illustrated in Figure 5, is witnessed in the wicking rate results of the plain weave fabrics of density 40 picks $/ \mathrm{cm}$, followed by 36 and 32 picks $/ \mathrm{cm}$ respectively. This can be attributed to the role of every intersection point which acts as a routing point to diffuse the water which causes the higher horizontal wicking rates.

\section{Conclusion}

In this study 9 woven PET textile samples varying in weave type and weave density were chosen to determine their effect on horizontal and vertical wicking rates.

After statistically analyzing the data, the results can be summarized as follows:

1. Vertical wicking rate was found to be greatly influenced by fabric porosity. This can be attributed to the fact that the increased porosity leads to the formation of more passages.

2. Horizontal wicking rate proved to be affected by the number of intersections per unit density which acts as routing points for the liquid. 
Citation: Nassar K, Abou-Taleb EM (2014) Effect of Selected Fabric Construction Elements on Wicking Rates of PET Fabrics. J Textile Sci Eng 4: 158. doi:10.4172/2165-8064.1000158

Page 5 of 5

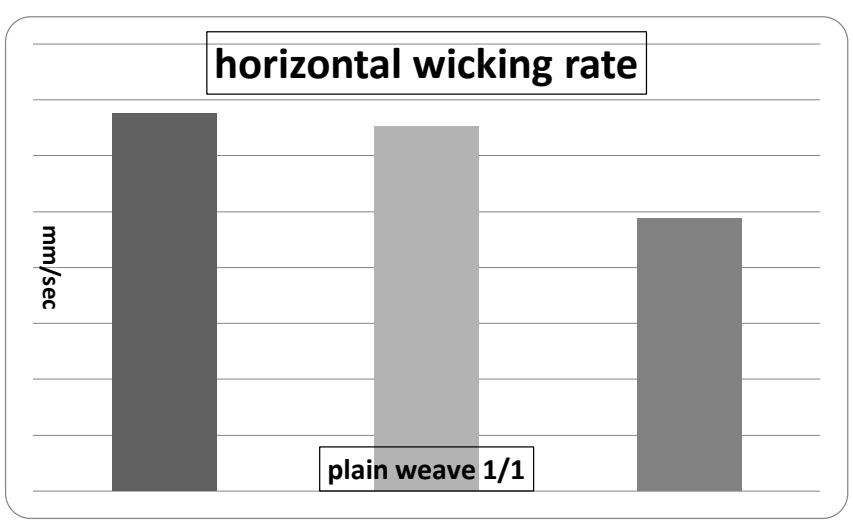

Figure 5: Horizontal wicking rate of plain weave at different densities.

3. Vertical wicking rate increases with the increase of the porosity, while horizontal wicking rate decreases with the increase of porosity.

\section{References}

1. Babu RV, Ramakrishnan G, Subramanian VS, Kantha L (2012) Analysis of Fabrics Structure on the Character of Wicking. J Eng Fibers Fabr 7: 28-33.
2. Chinta SK, Gujar MPD (2013) Significance of Moisture Management for High Performance Textile Fabrics. Int J Innov Res Sci Engg Technol 2: 814-816.

3. Fangueiro R, Filgueiras A, Soutinho F, Meidi X (2010) Wicking behavior and drying capability of functional knitted fabrics. Text Res J 80: 1522-1530.

4. Harnett PR, Mehta PN (1984) A Survey and Comparison of Laboratory Test Methods for Measuring Wicking. Text Res J 54: 471-478.

5. Ghali K, Jones B, Tracy J (1994) Experimental Techniques for Measuring Parameters Describing Wetting and Wicking in Fabrics. Text Res J 64: 106111.

6. Simile CB (2004) Critical evaluation of wicking in performance fabrics. SMARTech, Georgia Tech Library, USA.

7. Rieber G, Jiang J, Deter C, Chen N, Mitschang P (2013) Influence of textile parameters on the in-plane Permeability. Compos Part Appl Sci Manuf 52: 8998.

8. Hepburn CD (1988) The Wicking of Water Through Multi-Layer Fabric Assemblies. University of Leeds, UK.

9. Chu CC, Welch L (1985) Characterization of morphologic and mechanical properties of surgical mesh fabrics. J Biomed Mater Res 19: 903-916.

10. Horrocks AR, Anand S, Anand S (2000) Handbook of Technical Textiles. Woodhead Publishing, UK.

11. AATCC 197-2012 Vertical Wicking of Textiles. Thomson Reuters, USA.

12. AATCC 198-2012 Horizontal Wicking of Textiles. Thomson Reuters, USA. 